\title{
Effect of Various Infrared Heaters on Sintering Behavior of UHMWPE in Selective Inhibition Sintering Process

\author{
Tesfaye Kebede, Balasubramanian Esakki
}

\begin{abstract}
Selective inhibition sintering (SIS) is an emerging powder-based additive manufacturing technology that creates polymer or metal based parts through adhesion of layer-by-layer from three-dimensional computer-aided design model. Replacement of costly laser system in selective laser sintering tremendously reduces the cost of manufacturing. SIS attempts to incorporate low cost heaters to achieve efficient sintering for production of high quality parts. However, SIS demands uniform heating of each layer for effective sintering. The present study focused on examining the heating characteristics of three different types of infrared heaters with respect to various layer thickness and determining the optimal distance between the heating surface and the powder bed. Experiments are conducted using the low-cost heaters to obtain uniform distribution of heat energy across the ultra-high molecular weight polyethylene (UHMWPE) powder surface. The thermal and optical images are captured to observe the temperature distribution on the powder and the surface roughness. Tensile and compressive specimens were fabricated and their corresponding strength was determined and surface roughness was measured to study the surface characteristics of the parts.
\end{abstract}

Index Terms: Selective inhibition sintering (SIS)), Infrared heater, Polymer, Sintering.

\section{INTRODUCTION}

Sintering is a heat treatment process in which a definite amount of powder is exposed at elevated temperature and pressure, which is slightly less than the material's melting point, to fuse or coalescence the powder particles to produce a compact solid part. The procedure incorporates three main stages; neck development (i.e. consolidating contacting molecules), densification (i.e. development of interconnecting pores channels that leads to the onset of grain growth) and spheroidal molding and segregation of pores (i.e. pores collapse into closed spheres) [1]. At present, plasma initiated sintering [2], microwave sintering [3] and laser sintering [4] are considered as the ongoing advances in sintering technologies.The methods of polymeric powder

Revised Manuscript Received on October 30, 2019.

* Correspondence Author

Tesfaye Kebede Ali*, Department of Mechanical Engineering, Vel Tech Rangarajan Dr. Sagunthala R\&D Institute of Science and Technology, Chennai, India.

Balasubramanian Esakki, Department of Mechanical Engineering, Vel Tech Rangarajan Dr. Sagunthala R\&D Institute of Science and Technology, Chennai, India.

(c) The Authors. Published by Blue Eyes Intelligence Engineering and Sciences Publication (BEIESP). This is an open access article under the CC BY-NC-ND license (http://creativecommons.org/licenses/by-nc-nd/4.0/) sintering by additive manufacturing (AM) technologies have primarily focused on the use of lasers to fuse the powder particle together and to form layers. Although, laser sintering also referred to as selective laser sintering (SLS) is effective [4] and the time requires for lasers to scan the whole cross-section of the slice is high. It confines the speed of the sintering process, particularly for thick-walled parts. In addition, the necessity of expensive laser system and optics also drastically increase the cost of the machine. To cope up these issues, number of processes have been developed with faster speed of sintering and lower cost of machine. Selective inhibition sintering [5], electrophotographic layer manufacturing [6] and high-speed sintering [7] are the typical AM processes which can sinter powders without the use of laser Over the past three decay, different AM methods have been developed and grown into feasible options of producing objects and prototyping. Among these techniques, selective inhibition sintering (SIS), a new powder-based 3D printing technique, is one of the most promising AM technique due to its capability to produce less expensive, dimensionally accurate, multi-color parts with fast printing speed [5], [8]. Parts from polymer [5], metals [9] and ceramic [10] materials have been fabricated successfully using this process.

To introduce SIS process into industry for producing real components, good mechanical properties of manufactured part must be attained. These properties strongly depend on the proper sintering of every single layer as well as the strength of the bond between them. A. Aravind, T. N. Siddiqui, P. Arunkumar, and E. Balasubramanian [11] developed a robust sequential coupled field mode of finite element model to investigate thermal and structural characteristics of different high strength polymers. The simulation result revealed that the sintered part properties highly depend on the types of the polymer materials. Y. Shi, Z. Li, H. Sun, S. Huang, and F. Zeng [12] have pointed out that sintering phenomena of polymer intensely influenced by the properties of polymer materials (i.e. molten viscosity, molecular weight, particle size of the powder and crystallization rate). According to their study, higher density (SLS) parts can be produced from lower melting viscosity of polymer powder that is affected by their molecular weight. The sintered part precision and density of the parts highly influenced by the particle size of the powder and increasing crystallinity also lead to serious part shrinkage. Process parameters related to heating (i.e. heater power, heater feedrate, heater scanning distance, etc) and layer thickness have significant influence on sintering [13]. 
Researchers have also revealed that an increase in heater power [14], [15] up to certain level leads to increase in degree of sintering, but further increases leads to reducing in sintered part property due to degradation of power. B. Esakki, D. Rajamani and P. Arunkumar [8] have optimized the influences of four selected input parameters such as heater energy, printer feedrate, heater feedrate and layer thickness on the wear behavior of high-density polyethylene (HDPE) parts which were fabricated using SIS system. The ANOVA analysis of their experimental results figured out that layer thickness and heater energy were the principal influencing parameter of sliding wear and the fabricated part wear rate decrease with the decrease layer thickness and increase heater energy. D. Rajamani, E. Balasubramanian, P. Arunkumar, M. Silambarasan and G. Bhuvaneshwaran [16] examined the influence of process variable on shrinkage behavior of SIS parts using surface response methodology. Based on their result, layer thickness was critically dominant variable in influencing the shrinkage of parts. In the past, the effect of material properties and process variable on the quality of sintered parts have been studied in detail. However, no attempts have done to study the impact of heater design on attaining uniform sintering temperature across the powder particles for achieving uniformly sintered layer without burning on same part of the layer or being unsintered on the other part of the layer and its impact on the sintered part properties. Therefore, present research focused to examine the heating characteristics of three different low-cost infrared heaters (Table 1), on achieving uniform sintering over ultra-high molecular weight polyethylene powder surface, at different layer thickness and scanning space (i.e. distance between powder surface and infrared heater).

Table 1: Infrared heaters and their specifications

\begin{tabular}{|c|c|}
\hline Heater Type & Specifications \\
\hline $\begin{array}{l}\text { Short wave infrared heater } \\
\text { lamp (Clear quartz type) }\end{array}$ & $\begin{array}{l}\text { - Voltage } 240 \mathrm{~V} \\
\text { - } \text { Power } 500 \mathrm{~W} \\
\text { - } \text { Typical operating } \\
\text { temperature } 700{ }^{0} \mathrm{C} \\
\text { - Overall length } 212 \mathrm{~mm} \\
\text { - Heated Length } 127 \mathrm{~mm} \\
\text { - } \text { Response time around } 1 \\
\text { min }\end{array}$ \\
\hline $\begin{array}{l}\text { Ceramic infrared heater } \\
\text { (FTE series) }\end{array}$ & $\begin{array}{l}\text { - Voltage } 240 \mathrm{~V} \\
\text { - } \text { Power } 1000 \mathrm{~W} \\
\text { - } \text { Typical operating } \\
\text { temperature } 726{ }^{0} \mathrm{C} \\
\text { - } \text { Dimension } 245 \text { x } 60 \mathrm{x} \\
34 \mathrm{~mm} \\
\text { - } \text { Response time around } 5 \\
\text { min }\end{array}$ \\
\hline $\begin{array}{l}\text { Ceramic infrared heater } \\
\text { (HTS/1 series) }\end{array}$ & $\begin{array}{l}\text { - Voltage } 240 \mathrm{~V} \\
\text { - } \text { Power } 1000 \mathrm{~W} \\
\text { - } \text { Typical operating } \\
\text { temperature } 860{ }^{0} \mathrm{C} \\
\text { - } \text { Dimension } 245 \text { x } 60 \mathrm{x} \\
28 \mathrm{~mm} \\
\text { - } \text { Response time around } 5 \\
\text { min } \\
\end{array}$ \\
\hline
\end{tabular}

All objects that are above absolute zero temperature emit thermal radiation that is conveyed into the substrate in the form of electromagnetic wave. The substrate can absorb, reflect or transmit the radiation base on the wavelength of transferred radiation. The absorbed radiation only creates heat within the substrate. Infrared heating is applied in various industry, particularly for drying, baking, roasting, blanching, pasteurization, and sterilization. Reduced heat losses, fast heating time, simple and compact equipment design are some advantages of infrared heating over conventional methods [17], [18]. The ability of infrared heater to heat an object, depends on the wavelength, distance between heater and substrate, surface roughness and color of the substrate. In addition, the type of emitter material and its heating filament design also affect the characteristics of infrared heating. Therefore, the following three different types of infrared heaters namely short wave infrared heater lamp, HTS/1 serious ceramic infrared heater and Full Trough Emitter (FTE) serious ceramic infrared heater (Table 1) have been used by SIS process to examine their sintering characteristics over UHMWPE powder.

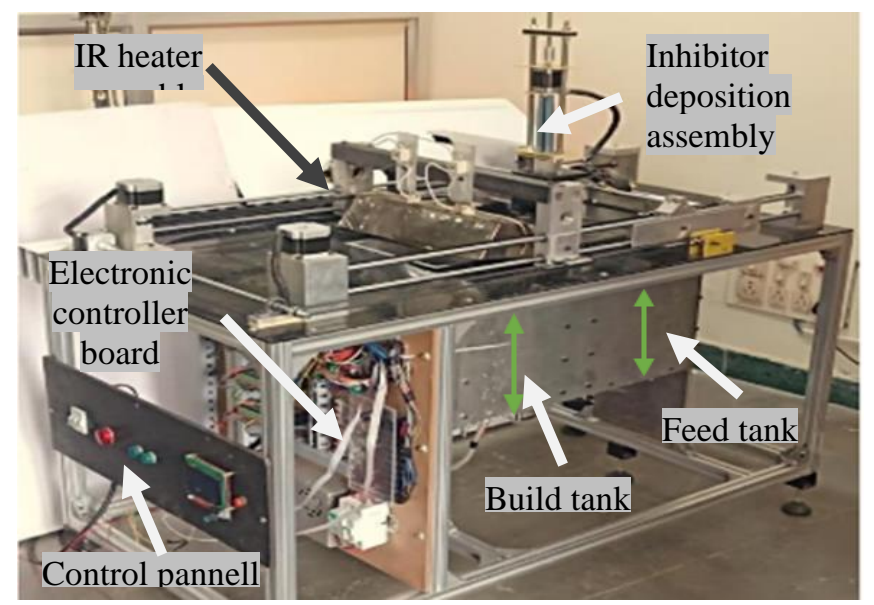

Fig. 1. Developed SIS system

\section{EXPERIMENTAL METHODS}

\section{A. Test Part Productions}

In order to realize the behavior of sintering, which could be attained by three different infrared heaters, a series of single-layered $200 \mathrm{~mm}$ x $200 \mathrm{~mm}$ rectangular parts were produced. The parts were built from UHMWPE powder using a self-developed laboratory SIS machine which is shown in Figure 1. The infrared heaters were attached to the moving parts of the machine, one at a time, to sinter the polymer powder. The heating property of each heater has been evaluated at different scanning space and powder layer thickness. Then, a suitable heater was selected based on the heater capability to produce homogeneous temperature distribution over the powder surface. During the experiment, the scanning speed was not changed and the part bed heater was kept switch off throughout the builds to maintain the consistency of the experiment. 


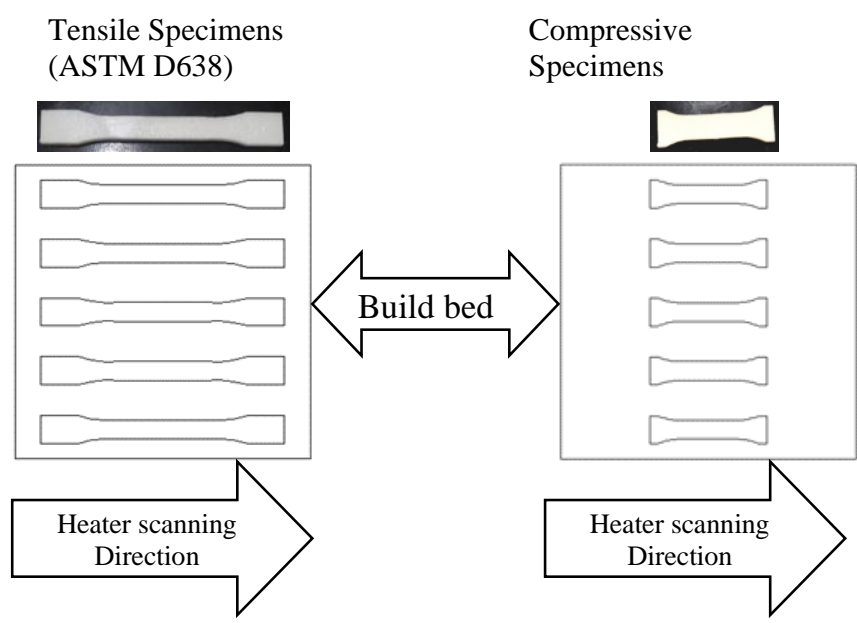

Fig. 2. Schematic view of the test specimens printing

\section{B. Strength Testing}

Five ASTM D638 Type 1 standard tensile test specimens and five ASTM D695 standard compressive test specimens were manufactured using the developed SIS machine with experimentally selected infrared heater (i.e. FTE ceramic infrared heater) at different location of build bed. As presented in figure 2, the length of specimens were parallel to the scanning direction of the heater. The strength tests were run on AC servo controlled ball screw type universal testing at ambient temperature with a constant crosshead speed of 5 $\mathrm{mm} / \mathrm{min}$. The tensile and compressive samples have $165 \mathrm{~mm}$ and $79.4 \mathrm{~mm}$ overall length respectively and manufactured over $200 \mathrm{~mm} \times 200 \mathrm{~mm}$ test region, with their length parallel to the scanning direction of the infrared heater.

\section{Surface Roughness Testing}

In this paper, surface roughness data of the top surfaces of SIS manufactured UHMWPE specimens were measured by the MarSurf PS1 / M300 roughness measuring instrument with tracing length $(\mathrm{Lc})$ of $5.6 \mathrm{~mm}$, tracing speed $(\mathrm{Vt})$ of $0.5 \mathrm{~mm} / \mathrm{s}$ and a sampling point of 1200 . During measurement of surface roughness, both parallel and perpendicular direction of the three tensile specmens with respect to the heater scanning direction of the heater were considred and taken the averge value. In addition, only the upper surface of the samples were measured, because the down surface of the samples strongly infulenced the build bed surface of the SIS system.

\section{RESULTS AND DISCUSSIONS}

A set of experiments were carried out to examine the sintering behavior of shortwave infrared quartz lamp, HTS/1 series ceramic infrared heater and FTE series ceramic infrared heater over the polymer powders. In order to find their optimal performance of the heaters, different scanning space and layer thickness of the powder has been considered during sintering. Then, the infrared heater with more uniform sintering behavior was selected for producing tensile specimens, which was used to study the strength of SIS parts. Thermal and optical camera images were used to visualize the temperature distribution. The states of fusion over the heating domain of infrared heaters at different scanning space and layer thickness. All the images were taken from one direction which is the length of the image is parallel to the heater scanning direction.

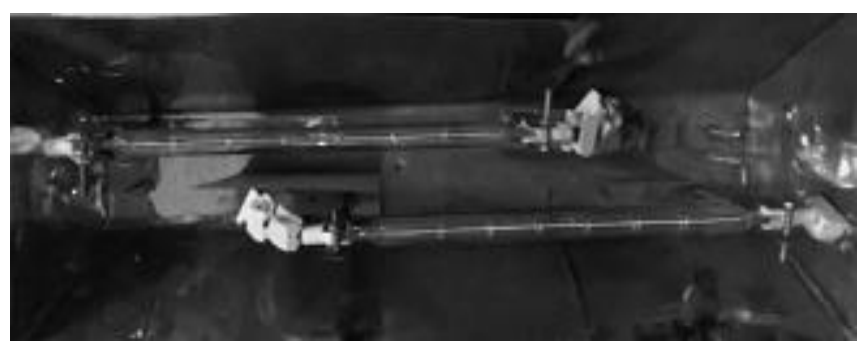

Fig 3. Arrangement of short wave IR heater lamp

\section{A. Effect of Infrared Heaters}

There have been wide variety of infrared heaters were utilized in industry with different emitter filament material and arrangement design [18] which significantly influence their sintering behaviors. Therefore, choosing the appropriate heater for a given heating pattern to achieve uniform temperature distribution is the main challenge. In this study, the method of choosing proper infrared heater depends on the level of accuracy to produce homogeneous sintering temperature over the polymer powder was explored. Here, figures 4 - 9 show thermal and optical images from the surface of single layer parts manufactured by the SIS machine and heated using various infrared heaters. As can be seen on the figures, significant temperature distribution difference was observed on the sintered sample manufactured by different infrared heaters. Even though, two short wave infrared lamp heaters with offset arrangement, as depicted in figure 3 , were considered in this study to extend the effective heating length. The thermal images of the sintered parts shown in the figures 4 and 5 revealed that, high temperature distribution has been observed at the central portion of the heating regions. Whereas, According to figures 6 and 7, the elevated temperature distribution has been shifted to the upper portion of the sintered parts using HTS/1 ceramic infrared heater. Generally, with HTS/1 series ceramic infrared heater and shortwave infrared quartz lamp, uneven sintering and temperature distribution observed over their heating region. Compared to the above discussed two heaters, FTS series ceramic infrared heater (figures 8 and 9) can produce reasonably homogenous sintering, at scanning space $15 \mathrm{~mm}$ and layer thickness $0.6 \mathrm{~mm}$.

\section{B. Effect of Scanning Space}

Scanning space has a significant effect on the behavior of sintering, as presented in figures 4, 6 and 8 . The thermal and optical images of the sintered parts clearly shows that with the decrease in scanning space from $30 \mathrm{~mm}$ to $15 \mathrm{~mm}$, there is a gradual increase in sintering depth and width. A decrease in scanning space leads to an increase in both the sintering width and depth, resulting into an increment of the intensity of infrared radiation [19], which means the radiation get extra energy to sinter the powder material. However, as the scanning space increases, the intensity of infrared radiation tends to decrease that leads in diminishing of sintering depth and width. 

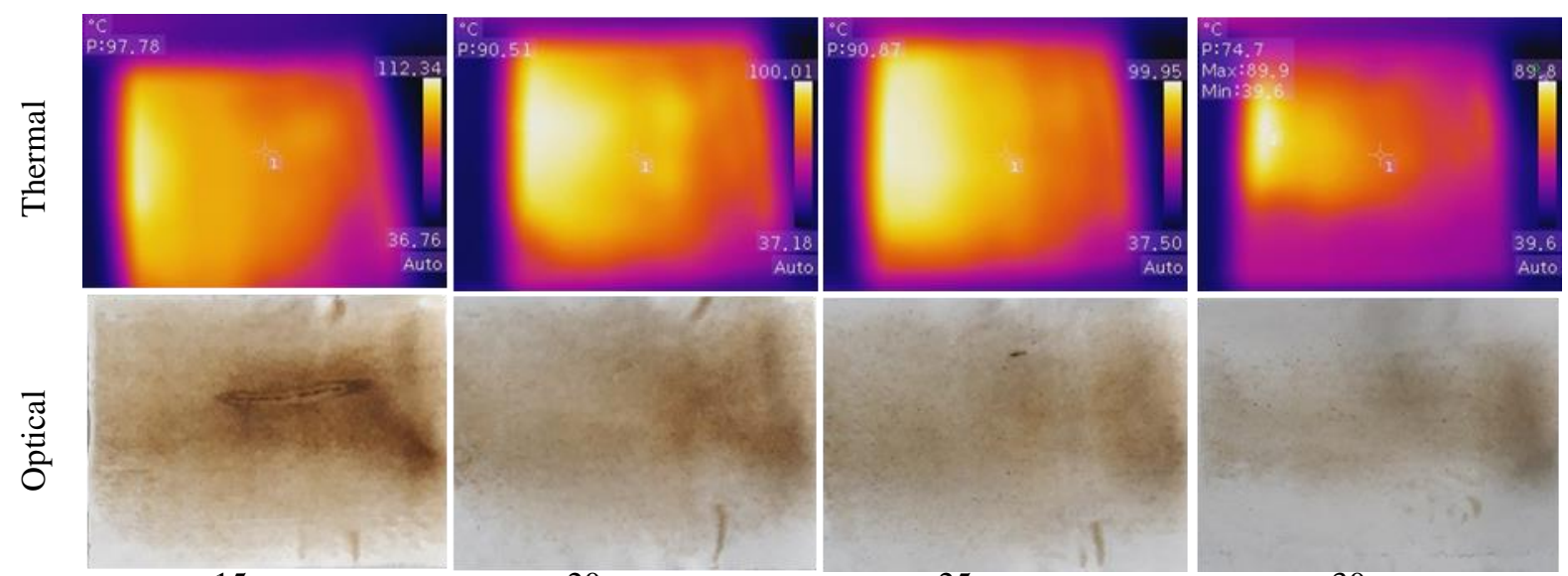

$20 \mathrm{~mm}$

$25 \mathrm{~mm}$

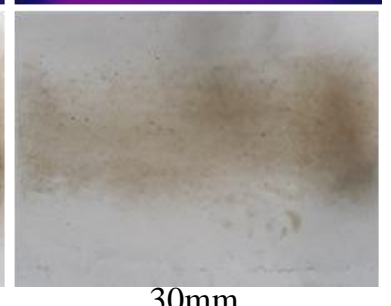

Fig. 4. Effect of scanning space using shortwave IR heater

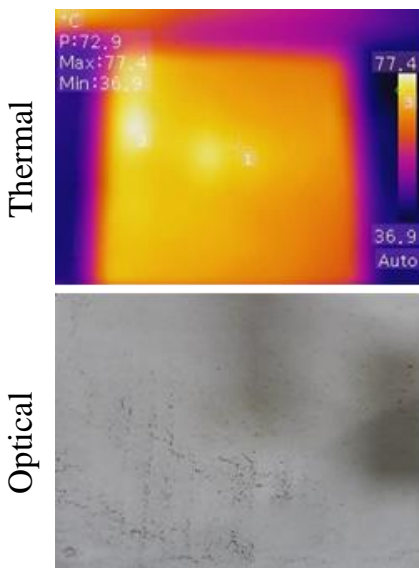

$0.3 \mathrm{~mm}$
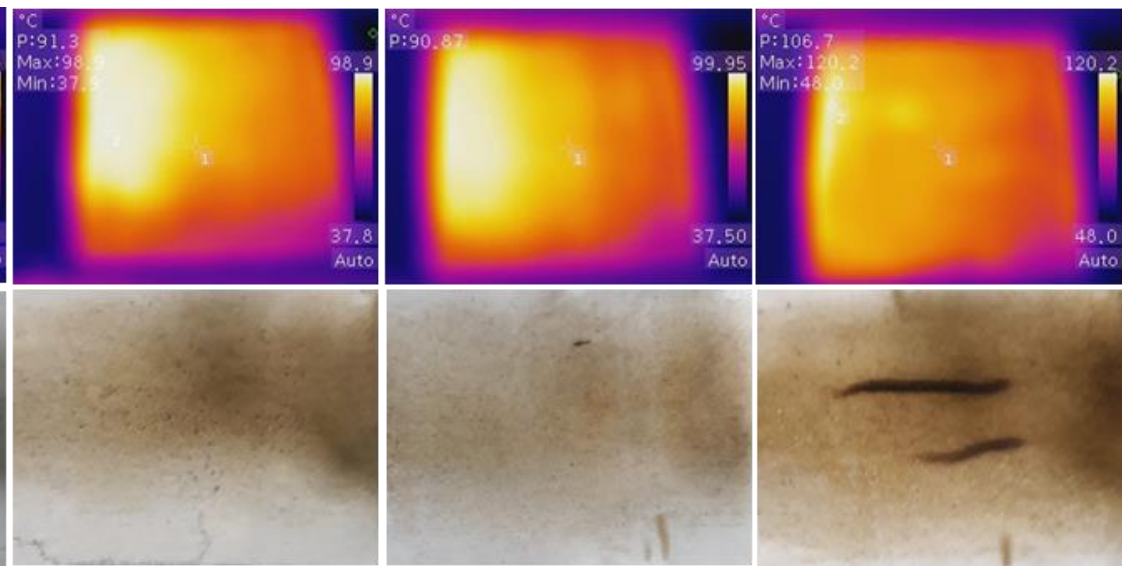

$0.6 \mathrm{~mm}$

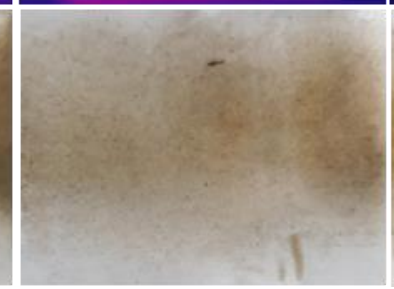

$0.9 \mathrm{~mm}$

$30 \mathrm{~mm}$

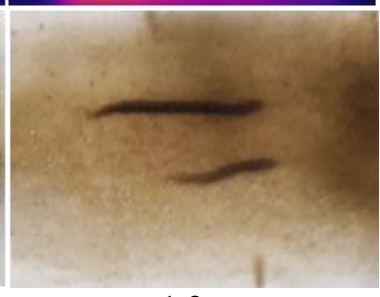

Fig. 5. Effect of layer thickness using shortwave IR heat

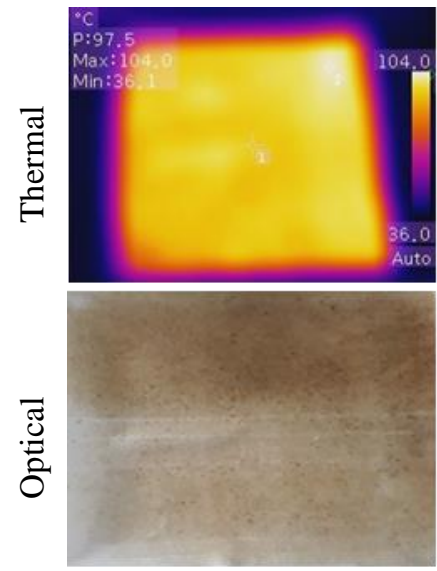

$15 \mathrm{~mm}$
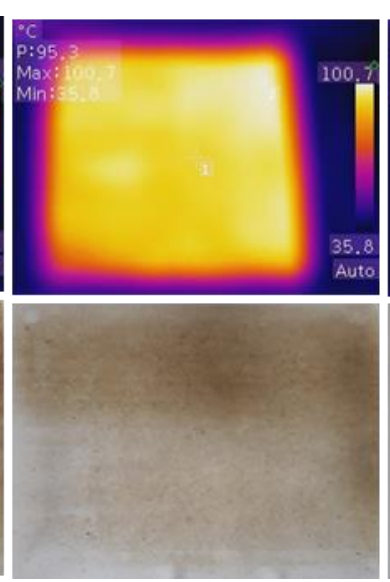

$20 \mathrm{~mm}$
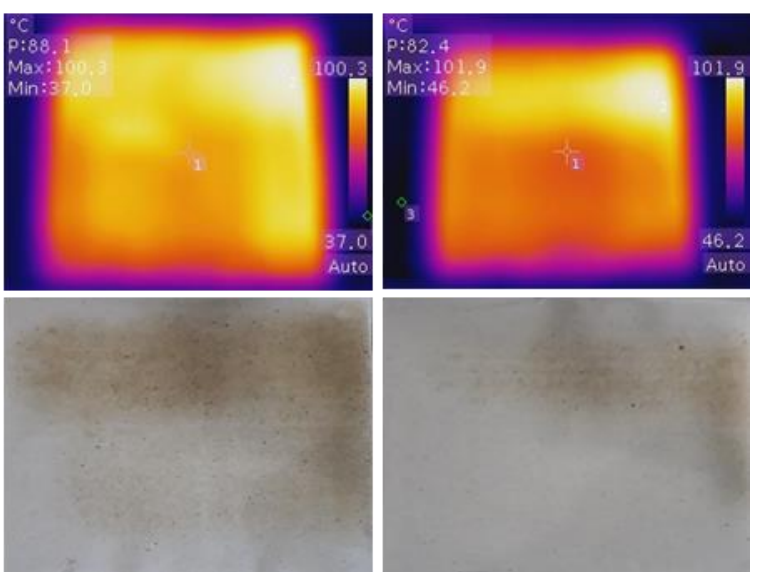

$25 \mathrm{~mm}$
$1.2 \mathrm{~mm}$

Fig. 6. Effect of scanning space using HTS/1 series ceramic infrared heater.

\section{A. Effect of Layer Thickness}

Influence of layer thickness on sintering of the powder can be seen in figures 5, 7 and 9. Furthermore, with the increase in layer thickness from $0.3 \mathrm{~mm}$ to $1.5 \mathrm{~mm}$, the sintering rate tends to increase at the upper surface of the powder. It may be happened because of the fact that, at smaller layer thickness the distance between powder particles is high, which takes long time to fuse the neighboring particles to fuse each other. However, higher proximity or compactness of powder particles easily achieved at higher layer thickness which leads in increasing the rate of sintering.

\section{B. Strength Properties}

Uneven temperature distribution over the powder is one of the serious issues for selective inhibition sintering process, which leads to variation in the mechanical properties [4] of the parts. The portion of the powder is exposed to high temperature became strong. Because, at high temperature the fusion of the powder particles is high and the revers has happened on the portion of the part with low sintering temperature [20].

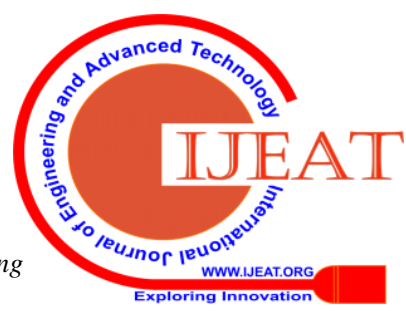




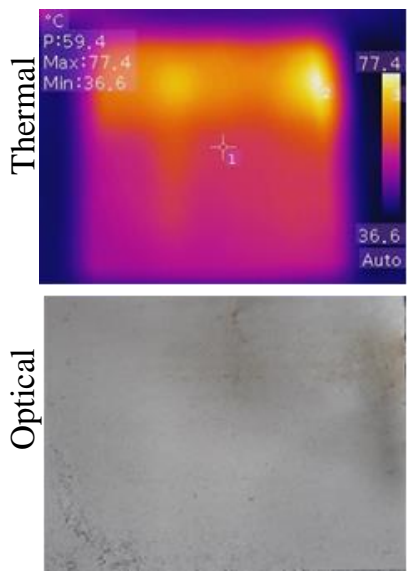

$0.3 \mathrm{~mm}$
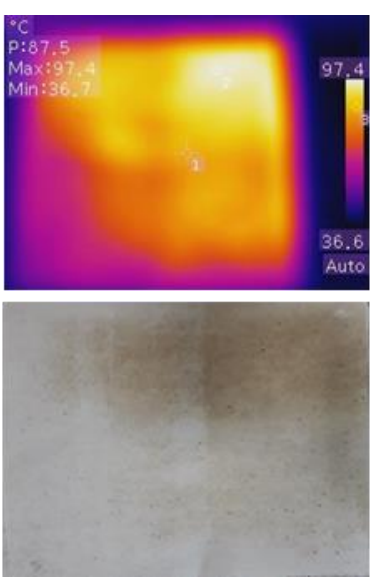

$0.6 \mathrm{~mm}$

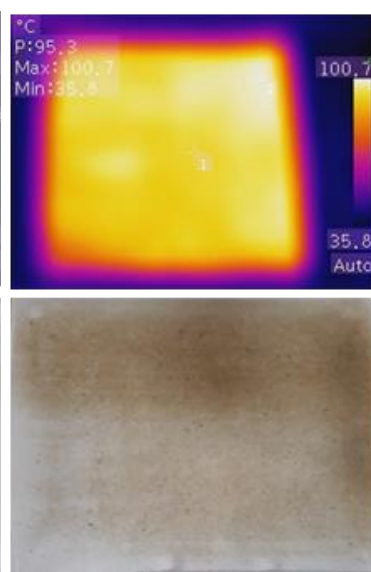

$0.9 \mathrm{~mm}$
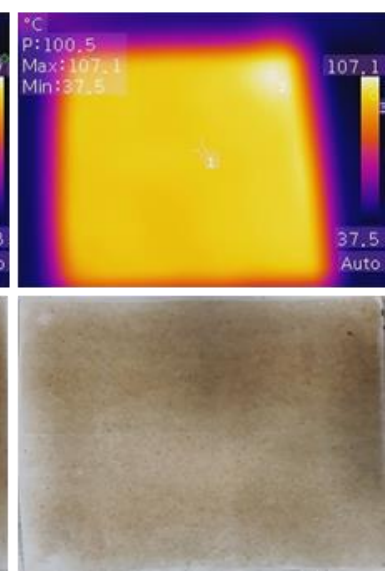

$1.2 \mathrm{~mm}$

Fig. 7. Effect of layer thickness using HTS/1 series ceramic infrared heater

Fig. 8. Effect of scanning space using FTE series ceramic infrared heater
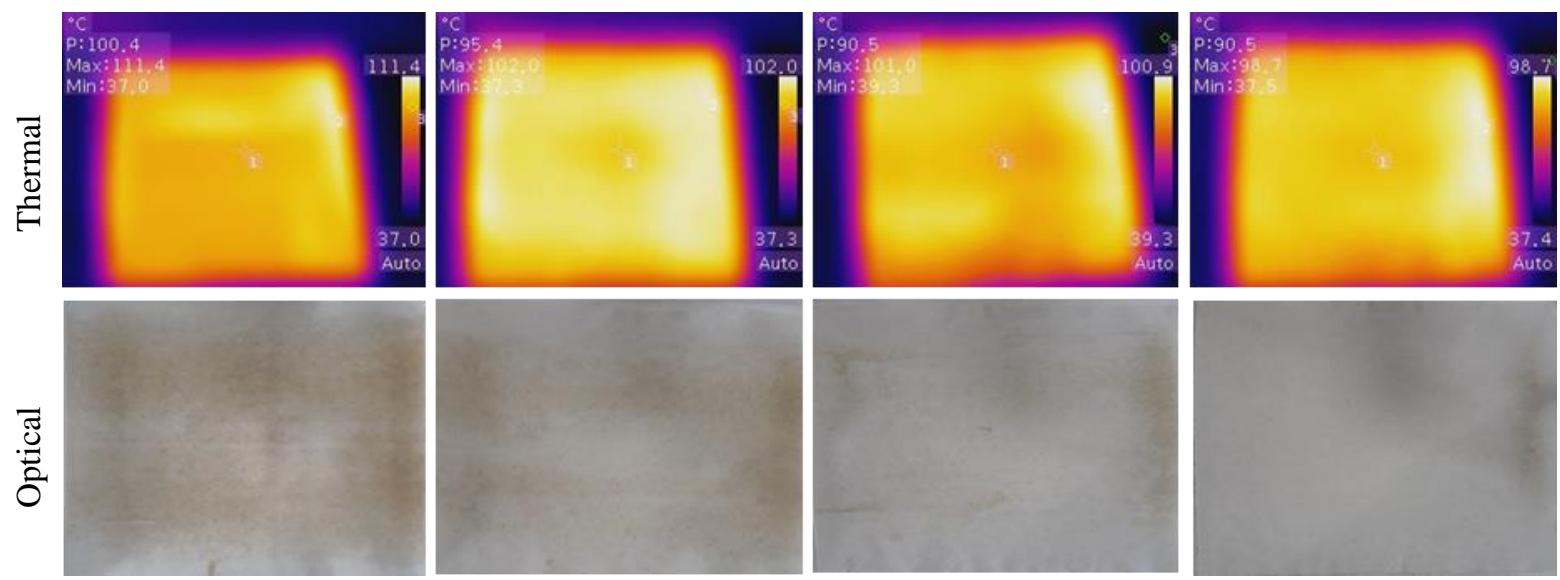

$20 \mathrm{~mm}$

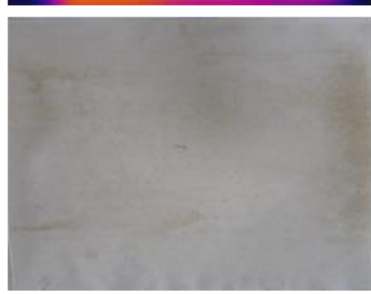

$25 \mathrm{~mm}$

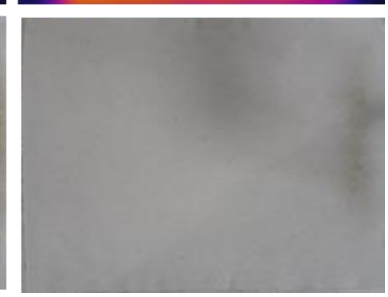

$30 \mathrm{~mm}$

Fig. 9. Effect of layer thickness using FTE series ceramic infrared heater
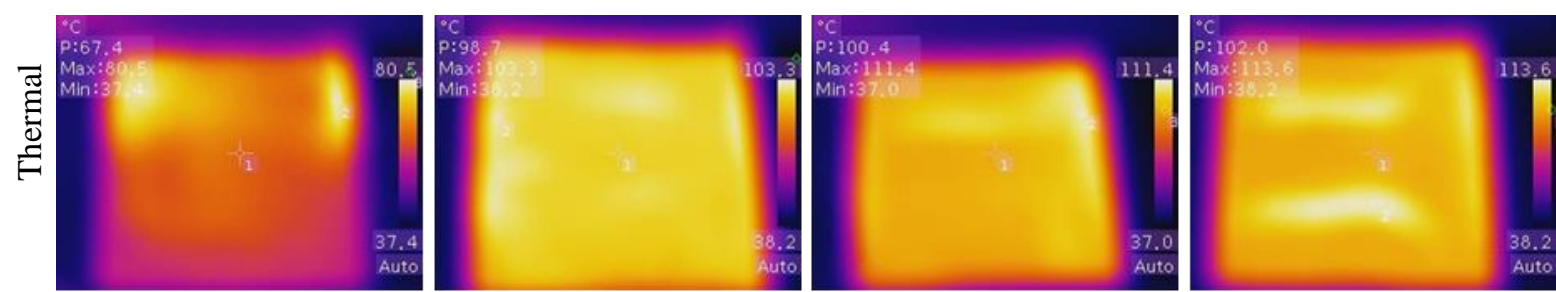

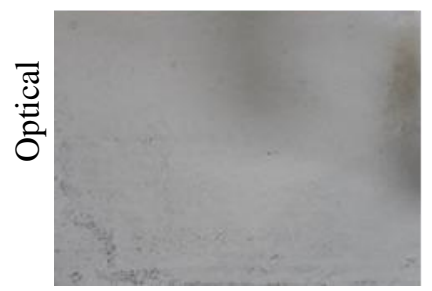

$0.3 \mathrm{~mm}$

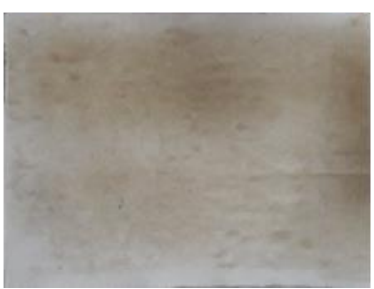

$0.6 \mathrm{~mm}$

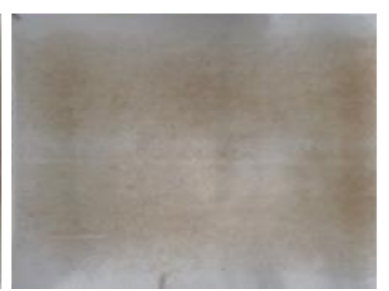

$0.9 \mathrm{~mm}$

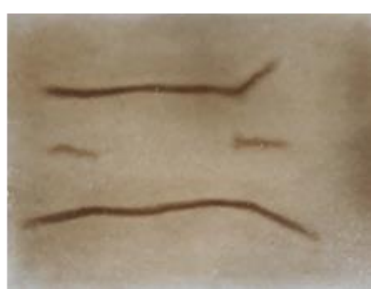

$1.2 \mathrm{~mm}$
Tensile and compressive strength tests were conducted to study the ability of FTE serious ceramic infrared heater to produce uniformly centered part. The Infrared heater produced UHMWPE parts with average tensile and compressive strength of $2.65 \pm 0.25 \mathrm{MPa}$ and $3.86 \pm 0.35$ $\mathrm{MPa}$ respectively. Stress-strain curves found from tensile and compressive test analysis are shown in Figure 10. During the tests, no significant difference is observed between the specimens in their ultimate stress and strain values. In additions, all specimens got broken in the middle part of narrow region of the specimens. A small variation in mechanical properties connected with the minimum variation in sintering temperature which means the ability of the selected heater, to produce uniform heating over the building bed, is good.

\section{A. Surface Roughness}

Surface roughness of the produced part is extremely important parameter during a

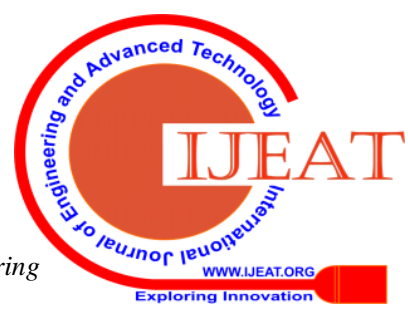




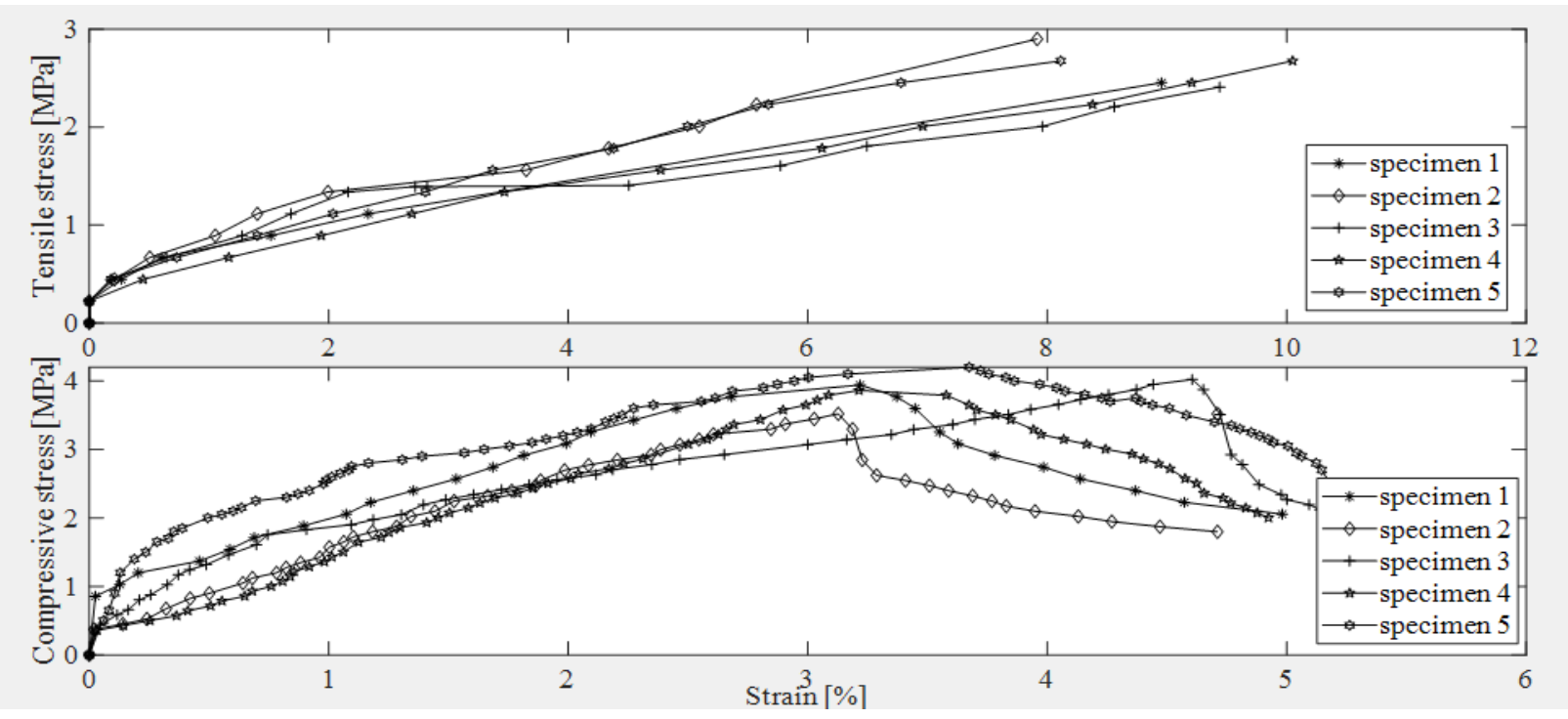

Fig. 10. Stress-strain curves of tested samples

manufacturing process, because it enormously influences the proper functioning and cost of a fabricated component. It is the measure of frequent surface irregularities that built in the fabrication process. Literature reveals that the surface roughness of the sintered parts influenced by many printing process parameters and heater sintering direction is one of the factors that affect surface quality of the produced parts. Present study considers both perpendicular directions during samples roughness measurement and Ra (arithmetic average roughness), which is the most commonly used indicator of surface roughness, was used to measure the roughness of the produced parts [21]. The SIS system, equipped with optimized FTE serious ceramic infrared heater (curved type), fabricated parts with average Ra value of $2.38 \pm 0.64 \mu \mathrm{m}$ in parallel and $2.29 \pm 0.52 \mu \mathrm{m}$ perpendicular to heater scanning direction is observed. The comparison between the various AM techniques manufactured components surface roughness is given in table 2. It is evident that SIS based manufacturing obtained lower surface roughness than other techniques. The decrease in surface roughness was found because of the uniform distribution of sintering temperature that lead to uniform fusion of powder particles. In addition, the variation of roughness on the parts between parallel and perpendicular heater direction is lower which shows the dependency of roughness on scanning direction is insignificant.

Table 2: Ra value of parts produced by other additive manufacturing techniques

\begin{tabular}{ccc}
\hline Process & Used Material & Min $\boldsymbol{R a}[\boldsymbol{\mu m}]$ \\
\hline SLM [22] & AlSi10Mg & 4.127 \\
FDM [23] & ABS plus-P430 & 2 \\
SLS [24] & Polyamide & 6.9 \\
SIS [25] & HDPE & 15.2 \\
SIS & UHMWPE & 1.74 \\
\hline
\end{tabular}

\section{CONCLUSIONS}

The present paper investigated the effect of ceramic and tungsten infrared heating elements on achieving uniform sintering phenomenon of UHMWPE powder surface. Experimental results revealed that the sintering temperature distribution strongly influenced by the types of infrared heater and FTE has obtained uniform heating in comparison to short wave infrared lamp and HTS /1 ceramic infrared heater. The elevated temperature distribution was obtained in the central portion of the sintered part using short wave infrared lamp heaters. The high temperature distribution was shifted to the upper portion of the part by HTS/1 serious ceramic infrared heater and approximately homogenous heat distribution pattern is observed using FTE ceramic infrared heater. However, scanning space and layer thickness have not much influenced on heat distribution pattern rather, significantly influence sintering depth and width of the powder. It is observed that powder fusion or bonding increases with an increase of layer thickness and decrease in scanning space. Optimized sintering depth and width was obtained at $0.6 \mathrm{~mm}$ layer thickness and $15 \mathrm{~mm}$ scanning space using FTE serious ceramic infrared heater which has obtained uniform temperature distribution. The tensile and compressive test specimens were successfully manufactured and corresponding strength characteristics were evaluated. A maximum ultimate tensile of $2.9 \mathrm{MPa}$ and compressive strength of 4.2 MPa and minimum arithmetic average surface roughness of $1.74 \mu \mathrm{m}$ were achieved with optimized layer thickness and scanning space. The surface roughness characteristics are superior than other AM techniques where in SIS obtained $1.74 \mu \mathrm{m}$ which is very minimal than other RP processes.

\section{REFERENCES}

1. Hornsby, P. R., and A. S. Maxwell. "Mechanism of Sintering between Polypropylene Beads.” Journal of Materials Science, vol. 27, no. 9, 1992, pp. 2525-33. 
2. Fan, X. A., et al. "Characterization and Thermoelectric Properties of P-Type 25\%Bi2Te3 -75\%Sb2Te3 Prepared via Mechanical Alloying and Plasma Activated Sintering." Journal of Physics D: Applied Physics, vol. 39, no. 4, 2006, pp. 740-45.

3. Oghbaei, Morteza, and Omid Mirzaee. "Microwave versus Conventional Sintering: A Review of Fundamentals, Advantages and Applications." Journal of Alloys and Compounds, vol. 494, no. 1-2, Elsevier B.V., 2010, pp. 175-89.

4. Goodridge, R. D., et al. "Laser Sintering of Polyamides and Other Polymers." Progress in Materials Science, vol. 57, no. 2, Elsevier Ltd, 2012, pp. 229-67.

5. Khoshnevis, Behrokh, Bahram Asiabanpour, et al. "SIS - A New SFF Method Based on Powder Sintering." Rapid Prototyping Journal, vol. 9 , no. 1,2003 , pp. 30-36

6. Kumar, Ashok V., and Anirban Dutta. "Electrophotographic Layered Manufacturing." Journal of Manufacturing Science and Engineering, vol. 126, no. 3 .

7. Hopkinson, N., and P. Erasenthiran. "High Speed Sintering - Early Research into a New Rapid Manufacturing Process." Solid Freeform Fabrication Symposium Proceedings, 2004, pp. 312-320.

8. Esakki, Balasubramanian, et al. "Modeling and Prediction of Optima Process Parameters in Wear Behaviour of Selective Inhibition Sintered High Density Polyethylene Parts." Progress in Additive Manufacturing, 2017, 3(3), 109-121.

9. Khoshnevis, B, et al. "Selective Inhibition Sintering for Fabrication of Metallic Parts.” IIE Annual Conference and Exhibition 2004, 2004, p. 731.

10. Khoshnevis, Behrokh, Jing Zhang, et al. "Ceramics 3D Printing by Selective Inhibition Sintering." Solid Freeform Fabrication Symposium, 2014, pp. 163-69.

11. Aravind, A., et al. "Comparative Study of High Performance Polymers in Selective Inhibition Sintering Process through Finite Element Analysis." Polymers and Polymer Composites, vol. 25, no. 3, 2017, pp. 199-202.

12. Shi, Y., et al. "Effect of the Properties of the Polymer Materials on the Quality of Selective Laser Sintering Parts." Proceedings of the I MECH E Part L Journal of Materials:Design and Applications, vol. 218, no. 3, 2004, pp. 247-52.

13. Asiabanpour. "Performance Factors in the Selective Inhibition of Sintering Process.” In IIE Annual Conference. Proceedings, 2003, p. 1.

14. Majewski, C. E., D. Oduye, et al. "Effect of Infra-Red Power Level on the Sintering Behaviour in the High Speed Sintering Process." Rapid Prototyping Journal, vol. 14, no. 3, 2008, pp. 155-60.

15. Majewski, C. E., B. S. Hobbs, et al. "Effect of Bed Temperature and Infra-Red Lamp Power on the Mechanical Properties of Parts Produced Using High-Speed Sintering." Virtual and Physical Prototyping, vol. 2, no. 2, 2007, pp. 103-10.

16. Rajamani, D., E. Balasubramanian, et al. "Experimental Investigations and Parametric Optimization of Process Parameters on Shrinkage Characteristics of Selective Inhibition Sintered High Density Polyethylene Parts." Experimental Techniques, vol. 42, no. 6, Experimental Techniques, 2018, pp. 631-44.

17. Krishnamurthy, Kathiravan, et al. "Infrared Heating in Food Processing: An Overview." Comprehensive Reviews in Food Science and Food Safety, vol. 7, no. 1, 2008, pp. 2-13.

18. Pan, Zhongli, et al. "Infrared Heating." Emerging Technologies for Food Processing, Second Edi, Elsevier Ltd, 2014 doi:10.1016/B978-0-12-411479-1.00025-5.

19. Emitters, Ceramic Infrared, and Technical Manual. "Ceramic Infrared Emitters Technical Manual.” Https://Www.Infraredheaters.Com/Page3.Html, no. 01873, pp. 1-21.

20. Tontowi, Alva E., and T. H. C. Childs. "Rapid Prototyping Journal Density Prediction of Crystalline Polymer Sintered Parts at Various Powder Bed Temperatures.” Rapid Prototyping Journal Iss Rapid Prototyping Journal Iss Assembly Automation Iss Rapid Prototyping Journal, vol. 7, no. 14, 1997, pp. 180-84.

21. Shi, Dongping, and Ian Gibson. "Surface Finishing of Selective Laser Sintering Parts with Robot." Proceedings of the 9th Solid Freeform Fabrication Symposium, Austin, Texas, 1998, pp. 27-35.

22. Wang, Lin zhi, et al. "Experimental Investigation on Densification Behavior and Surface Roughness of AlSi10Mg Powders Produced by Selective Laser Melting." Optics and Laser Technology, vol. 96, Elsevier Ltd, 2017, pp. 88-96.

23. Durgun, Ismail, and Rukiye Ertan. "Experimental Investigation of FDM Process for Improvement of Mechanical Properties and Production Cost." Rapid Prototyping Journal, vol. 20, no. 3, 2014, pp. 228-35.

24. Sachdeva, Anish, et al. "Investigating Surface Roughness of Parts Produced by SLS Process." International Journal of Advanced Manufacturing Technology, vol. 64, no. 9-12, 2013, pp. 1505-16.
25. Rajamani, D., Aiman Ziout, et al. "Prediction and Analysis of Surface Roughness in Selective Inhibition Sintered High-Density Polyethylene Parts: A Parametric Approach Using Response Surface Methodology-Grey Relational Analysis." Advances in Mechanical Engineering, vol. 10, no. 12, 2018, pp. 1-16.

\section{AUTHORS PROFILE}

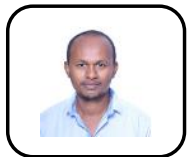

Tesfaye Kebede is a mechanical engineer with the qualification of Masters of Science (M.Sc.) degree and conducting research affiliated to Vel Tech Rangarajan Dr. Sagunthala R\&D Institute of Science And Technology. His research focus areas are rapid prototyping and

mechatronics

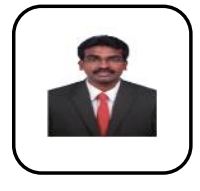

Dr. E. Balasubramanian is associate professor of mechanical engineering and Head - Centre for Autonomous System Research, Research Park, Vel Tech Rangarajan Dr Sagunthala R \& D Institute of Science and and Rapid prototyping. 